\title{
Cursos superiores de tecnologia em gestão: reflexões e implicações da expansão de uma (nova) modalidade de ensino superior em administração no Brasil*
}

\author{
Adriana Roseli Wünsch Takahashi**
}

Sumário: 1. Introdução; 2. Contexto do setor educacional profissional de nível tecnológico no Brasil; 3. Discussões e reflexões; 4. Considerações finais.

Summary: 1 . Introduction; 2 . Context of the professional education sector at the technological level in Brazil; 3. Discussions and reflections; 4. Final remarks.

Palavras-chave: cursos superiores de tecnologia; educação profissional; administração.

KEY WORDs: higher education courses in technology; professional education; management.

A partir da Lei de Diretrizes e Bases (LDB), Lei no 9.394/96, a educação profissional tem passado por profundas mudanças no Brasil. Os cursos superiores de tecnologia (CSTs), que existem desde os anos 1970, foram reformulados a fim de atender às demandas atuais do setor produtivo e ampliar o acesso ao ensino superior. As políticas públicas federais têm fomentado o crescimento da oferta da educação profissional tecnológica superior brasileira, em nível de graduação e pós-graduação, o que pode ser observado nos dados censitários. Tal fato suscita a reflexão de algumas questões.

\footnotetext{
*Artigo recebido em out. 2008 e aceito em nov. 2009. A elaboração deste artigo foi possível graças ao suporte financeiro fornecido pelos programas de bolsa da Coordenação de Aperfeiçoamento de Pessoal de Nível Superior (Capes). A autora é grata aos revisores do artigo por suas contribuições para este trabalho, ao debatedor prof. Pedro Lincoln C. L. De Mattos (Programa de Pós-Graduação em Administração da Universidade Federal de Pernambuco) e demais participantes da sessão, que fizeram sugestões importantes quando da sua primeira apresentação no 32을 Enanpad 2008.

**Doutora em administração pela Faculdade de Economia e Administração da Universidade de São Paulo (FEA/USP), professora de administração na Universidade Federal do Paraná. Endereço: Av. Prefeito Lothário Meissner, 632 - Jardim Botânico - CEP 80210-170, Curitiba, PR, Brasil. E-mail: adrianarwt@terra.com.br.
} 
O que a expansão desses cursos significa para a área de administração? Em que eles são diferentes dos tradicionais cursos de bacharelado? Qual a importância de analisar essa modalidade de ensino? De forma geral, o que representa para o cenário nacional essa mudança no ensino superior brasileiro? Mediante tais considerações e com base em pesquisa bibliográfica e documental em dados secundários, este artigo propõe um debate sobre os possíveis impactos desse crescimento para a própria modalidade de ensino, para as instituições ofertantes e para o ensino em administração no Brasil. Por fim, a partir de tais questionamentos, busca-se oferecer elementos para a organização de uma agenda de pesquisas com vistas ao acompanhamento da expansão dos CSTs em administração.

Higher education courses in management technology: reflections and implications of the expansion of a (new) modality of higher education in management in Brazil

Since Act 9394/96, professional education has been going through great changes in Brazil. The higher education technological courses (CSTs) that exist since the seventies have been reformulated to answer the now existing demands of the production sector and to improve the access to higher education. Federal public policies have stimulated professional education in technology, expanding its offering of courses for both undergraduate and graduate studies, as census data can show. This brings up a few questions. What does this expansion mean to the management area? In which way are these courses different from those with a bachelor's degree? What is the importance of analyzing this standard of education? What does this change in Brazilian higher education mean to the country? Taking the previous reflection into account and based on documentary and bibliographical research in secondary data, this article proposes a debate on the possible impacts of this increase in this kind of education itself, in the institutions that offer it and to management education in Brazil. It then presents elements for organizing a research agenda dealing with the expansion of the CSTs in managemen.

\section{Introdução}

Diversos estudos têm se voltado à reflexão sobre o ensino superior em administração no Brasil. Pesquisadores e docentes, sob diferentes enfoques, têm se mostrado preocupados com sua configuração e expansão, seja em determinadas localidades (Canopf, Festinalli e Ichikawa, 2005), na administração (Oliveira e Sauerbronn, 2007; Silva e Fischer, 2008) ou especificamente na administração pública (Coelho, 2008), na graduação presencial e na graduação a distância (Torrecillas e Miramar, 2008), ou mesmo na pós-graduação (Wood Jr. e Paula, 2004; Viana, Mantovani e Vieira, 2008). As conclusões variam das constatações sobre o ensino atual em administração a proposições e 
opções futuras das escolas e do ensino em administração no Brasil e no mundo (Fischer, 2001; Friga, Bettis e Sullivan, 2004).

Contudo, poucos estudos têm apresentado como recorte específico do ensino superior em administração os cursos de graduação situados dentro da educação profissional. Atualmente, de acordo com o Decreto ํo 5.154/2004, a educação profissional no Brasil consiste de três níveis, sendo um deles a educação profissional tecnológica de graduação e de pós-graduação. Neste nível, estão os cursos superiores de tecnologia (CSTs), cursos de graduação também conhecidos como cursos tecnológicos ou tecnólogos.

Os CSTs começaram a ser ofertados na educação profissional brasileira na década de 1970, em função da necessidade de formação e qualificação de trabalhadores para atender à demanda das empresas instaladas no período de industrialização e modernização promovido pelo governo brasileiro em meados do século XX. No entanto, persistia a visão de uma educação para o trabalho associada à formação profissional das classes menos favorecidas. Essa iniciativa não alterou a mentalidade das elites, um pensamento privilegiava, especificamente, os cursos superiores plenos. A influência histórica que marcou o preconceito manteve-se sobre a educação profissional.

Ao longo das últimas seis décadas, a inovação nos processos produtivos passou a requerer cada vez mais dos trabalhadores uma escolaridade básica acompanhada de contínua qualificação profissional. Nos últimos 10 anos, o Brasil passou então a fomentar a educação profissional de nível superior como uma resposta estratégica tanto de escolarização quanto de atendimento ao setor produtivo. Alguns fatores parecem ter pressionado essa iniciativa. Um deles é que há um contingente expressivo de alunos formados no Ensino Médio buscando a continuidade dos estudos, resultado da ampliação das vagas na educação básica nos últimos 10 anos. O segundo fator é a pressão que a chamada economia baseada no conhecimento (EBC) coloca sobre os sistemas educacionais para qualificar os trabalhadores de forma que as organizacões possam inserir-se na economia globalizada. Um terceiro é a tendência educacional mundial de investimentos na educação profissional. Nos Estados Unidos e em alguns países da Europa, mais da metade dos alunos formados no Ensino Superior se forma nessa modalidade de ensino (Parecer CNE/CES no 436/2001).

A partir da nova LDB, conhecida pelo nome de seu idealizador - Lei Darcy Ribeiro -, que entende ser a educação profissional integrada às diferentes formas de educação (Parecer CNE/CP no 29/2002), esse preconceito começou a ser alterado. A partir dessa lei e das regulamentações posteriores, a educação profissional foi redimensionada, e o ensino tecnológico reiniciou sua trajetória no Bra- 
sil. A organização e o incentivo dados pela Secretaria de Educação Profissional e Tecnológica (Setec/MEC) a essa modalidade educacional trouxeram uma nova perspectiva de formação superior para o Brasil que já existe em outros países (Parecer CNE/CES no 436/2001). A partir de então, instituições públicas de ensino revitalizaram seus cursos e os primeiros centros de educação tecnológica (CETs) começaram a ser credenciados pela iniciativa privada (Anet, 2003:4).

Os CSTs tiveram um significativo crescimento quanto ao número de vagas, de alunos matriculados e de instituições ofertantes, nos últimos cinco anos no Brasil. Esses cursos são graduações voltadas ao mundo do trabalho, à inovação científica e tecnológica e à gestão de produção e serviços. A principal diferença entre os cursos de graduação tecnológicos, que conferem o diploma de tecnólogo, e os cursos tradicionais de Ensino Superior, que conferem o diploma de licenciatura ou bacharel, está na proposta e nos propósitos de cada um. Os cursos tecnológicos vêm atender a uma demanda do mercado por especialistas dentro de uma área de conhecimento e estão orientados por características como foco, rapidez e flexibilidade, enquanto as outras modalidades de ensino superior visam formar generalistas. Os CSTs são, portanto, cursos distintos das graduações tradicionais (Parecer CNE/CES no 436/2001), e seus concluintes ficam aptos a prosseguir seus estudos em nível de pós-graduação.

No Brasil, houve um rápido crescimento dos CSTs a partir de 1999. Segundo o Censo da Educação Profissional, os cursos tecnológicos cresceram 74\% entre 2000-02. Em 1999, as faculdades e os CETs ofereciam 74 cursos tecnológicos, enquanto em 2004 esse número passou para 758. Entre estes, $51,8 \%$ pertenciam ao setor privado e $48,2 \%$ eram ofertados pelo setor público (Inep, 2008). Apontado pela mídia como o "novo filão do mercado", esses cursos tendem a continuar a crescer. Em 2006, os CSTs representavam 15\% das graduações nacionais (MEC, 2006b). A sociedade tem dado respostas ao crescimento da oferta por meio da rápida absorção do tecnólogo no mercado de trabalho. Apesar de ainda modesta, comparando ao universo de cursos superiores de graduação tradicional, a oferta dessa modalidade tem sido legitimada nos últimos anos pela regulamentação do MEC e pela crescente aceitação social dos cursos.

O Censo da Educação Superior de 2006 do Instituto Nacional de Estudos e Pesquisas (Inep) demonstra que a área de administração é uma das mais procuradas. Segundo esses dados, dos 736.829 alunos que concluíram cursos de graduação presencial - bacharelados, licenciaturas e tecnológicos - em 2006, 299.246 alunos estão na grande área de ciências sociais, negócios e direito, ou seja, 40,61\%. Entre estes, 123.816 alunos estão nas áreas específicas 
de comércio e administração e de gerenciamento e administração, ou seja, 16,8\% (Inep, 2008).

O mesmo crescimento tem sido observado nos CSTs em gestão, apesar de não se dispor de informações tão detalhadas quanto as referentes ao Ensino Superior em geral. O predomínio dos cursos superiores em administração no Brasil traz novos desafios ao campo, pois há um contingente de alunos formados com um perfil diferenciado, de especialista nas áreas de gestão. A formação desses alunos demanda dos docentes práticas de ensino específicas e pedagogias próprias. Além disso, uma parcela dos tecnólogos formados passa a buscar continuidade nos estudos em cursos de pós-graduação, uma vez que legalmente estão habilitados para tal, inclusive nos cursos stricto sensu. Todos esses fatos afetam o grande campo da administração, de graduação e pós-graduação, bem como a atuação dos professores e pesquisadores. Refletir sobre essas questões é o principal desafio deste artigo. No entanto, para discutir sobre esta realidade é necessário compreender o que são os CSTs. Para isso, com base em pesquisa realizada com dados secundários, descreve-se sua história, especificidades e crescimento para compreender sua existência e analisar sua inserção no Ensino Superior. Por fim, são apresentados questionamentos que possam auxiliar a organização de uma agenda de pesquisas sobre o tema com vistas ao acompanhamento do crescimento acadêmico (instituições e docentes) e profissional (alunos) relacionado aos cursos tecnológicos em gestão.

\section{Contexto do setor educacional profissional de nível tecnológico no Brasil}

Os cursos de educação profissional tecnológica de graduação fazem parte da oferta total de Ensino Superior brasileiro. Enquanto em anos anteriores sua participação no cenário educacional nacional era tímida e até mesmo desconhecida, em termos gerais, agora estes cursos vêm crescendo e se solidificando na rede de ensino, pública e privada, tornando-se reconhecidos e, gradativamente, aceitos no mercado de trabalho e na sociedade. Esse panorama começa a alterar-se a partir da nova LDB, quando a educação profissional começa a passar por profundas mudanças no Brasil. Com isso, o mesmo crescimento que pode ser observado na oferta de cursos bacharelados na área de administração, também é visto nos cursos tecnológicos, ou CSTs, em gestão. Para explorar este cenário, serão enfocados os aspectos legais e os dados estatísticos que são relevantes para alcançar o objetivo do artigo. 


\section{O Ensino Superior no Brasil}

O Censo 2006 sobre o Ensino Superior no Brasil, realizado pelo Inep, registrou a existência de 2.270 instituições de educação superior (IES), sendo 248 públicas $(10,92 \%)$ e 2.022 privadas $(89,08 \%)$. Segundo o World Education Indicators, este é um dos sistemas mais privatizado do mundo, atrás de alguns poucos países. Entre as IES públicas, 97 são federais, 75 são estaduais e 59 são municipais. De acordo com o mesmo Censo, entre as IES privadas há dois grupos: as particulares com fins lucrativos, que somam $1.583(78,3 \%)$, e as comunitárias, filantrópicas ou confessionais, que somam 439 (21,7\%). Em relação aos censos anteriores, a comparação dos dados mostra que a educação superior no Brasil continua em expansão acelerada, principalmente nas IES privadas (Inep, 2008).

O quadro 1 aponta as 10 maiores instituições brasileiras com base nas matrículas nos cursos de graduação presencial e ilustra a intensidade da expansão das instituições privadas. Entre as 10 , sete são privadas e três são estaduais.

Quadro 1

Relação das 10 maiores instituições em número de matrículas na graduação presencial (Brasil - 2003)

\begin{tabular}{|lccc|}
\hline Instituição & UF & $\begin{array}{c}\text { Categoria } \\
\text { administrativa }\end{array}$ & Matrícula \\
\hline Universidade Estácio de Sá & RJ & Privada & 100.617 \\
Universidade Paulista & SP & Privada & 92.023 \\
Universidade de São Paulo & SP & Estadual & 44.281 \\
Universidade Luterana do Brasil & RS & Privada & 41.450 \\
Pontifícia Universidade Católica de Minas Gerais & MG & Privada & 36.749 \\
Universidade Salgado de Oliveira & RJ & Privada & 35.719 \\
Universidade Estadual do Piaú & PI & Estadual & 35.683 \\
Universidade Estadual de Goiás & GO & Estadual & 34.113 \\
Universidade Bandeirante de São Paulo & SP & Privada & 32.852 \\
Universidade do Vale do Rio dos Sinos & RS & Privada & 31.482 \\
\hline
\end{tabular}

Fonte: Inep/MEC. Disponível em: <www.inep.gov.br/download/superior/censo/2004/resumo_tecnico_050105. pdf>. Acesso em: set. 2005.

Os dados desta década evidenciam o crescimento do ensino superior. O Censo 2003 apontou um acréscimo de 2.054 novos cursos em relação a 2002. 
Surgiram 5,6 novos cursos a cada dia no Brasil em 2003, dos quais 4,5 foram criados no setor privado e 1,1 no setor público. O mesmo censo registrou a existência de 16.453 cursos presenciais de ensino superior, dos quais 10.791 $(65,58 \%)$ na rede privada. O Censo 2005 apontou a existência de 20.407 cursos de graduação presencial, sendo 6.191 (30,33\%) em IES públicas e 14.216 $(69,67 \%)$ em IES privadas. O Censo 2006 identificou 22.101 cursos de graduação presencial, sendo $6.549(29,6 \%)$ na rede pública e $15.552(70,4 \%)$ na rede privada. Portanto, entre 2002 e 2006 observa-se uma variação de 14.399 cursos de graduação presencial para 22.101, um crescimento de 53,49\%, com a manutenção do predomínio da rede privada.

Esse cenário é confirmado pelo número de matrículas. O Censo 2006 apontou um total de 4.676 .646 alunos efetivamente matriculados nos cursos de graduação presencial, sendo $25,85 \%$ na rede pública e $74,15 \%$ na rede privada. Entre eles, 98.137 alunos (22\%) estavam matriculados especificamente em CETs e faculdades de tecnologia (nova denominação legal para os CETs). Cabe ressaltar que não somente os CETs ofertam os cursos tecnológicos, que são também ofertados em outras categorias de IES como universidades, centros universitários, faculdades integradas, faculdades, escolas e institutos. Porém, não há no censo o registro específico para a modalidade dos cursos tecnológicos, considerando-se todos os ofertantes.

Cabe ressaltar que, apesar da rápida expansão dos cursos superiores no Brasil, houve também o crescimento da evasão dos alunos. Enquanto o número de matrículas nos últimos 10 anos aumentou $134 \%$ e o de ingressantes $172,6 \%$, o número de concluintes, apesar de também aumentar, não acompanhou o mesmo crescimento, sendo de $114,7 \%$.

\section{O Ensino Superior em administração no Brasil}

No cenário de expansão do ensino superior no Brasil, observa-se também a expansão dos cursos de administração. Os primeiros cursos de administração surgiram em 1941, quando nos Estados Unidos já se formavam em torno de 50 mil bacharéis, 4 mil mestres e 100 doutores por ano nessa área (Castro, 1981). A partir da década de 1940, a profissionalização do ensino de administração destacou-se em função da necessidade de mão de obra qualificada (Martins, 1989) no processo de desenvolvimento econômico do país. A partir da década de 1960, o ensino superior intensificou-se (Couvre, 1982).

De acordo com Martins (1989), duas instituições marcaram essa expansão: a Faculdade de Economia e Administração da Universidade de São Paulo 
(FEA/USP) e a Fundação Getulio Vargas (FGV). A criação e a evolução dos cursos de administração, de acordo com o Conselho Regional de Administração (CRA-SP), se deram em instituições universitárias que se tornaram centros de excelência e de referência no ensino e pesquisa. Porém, a partir dos anos 1960 , os cursos se expandiram em faculdades isoladas e privadas que proliferaram na sociedade.

Posteriormente, em 1965, a atividade do administrador foi regulamentada no nível de Ensino Superior pela Lei no 4.769, e seu currículo foi fixado pelo Conselho Federal de Educação pela Lei no 4.024 de 1961. Esses fatos ampliaram o campo de formação do administrador. Em 1966 foi fixado o primeiro currículo do curso de administração, ficando assim institucionalizada a profissão e a formação (CRA-SP).

De acordo com Castro (1981), o ensino de administração passou de dois cursos em 1954 para 31 em 1967, para 177 em 1973, posteriormente para 244 em 1978, chegando em 454 em 1995. No início da década de 1980, o setor privado já reafirmava-se como maior ofertante dos cursos de administração, sendo responsável por aproximadamente $79 \%$ dos alunos. Quanto às regiões de oferta, no início da década de 1980 as regiões Sudeste e Sul já respondiam por $81 \%$ de todo o ensino de administração do país. Em 1995, 76\% dos cursos continuavam nessas regiões (CRA-SP).

Segundo o Censo 2003, dos 3.887.022 alunos de cursos de graduação presencial, 27,6\% estavam em dois cursos: administração com 564.681 $(14,5 \%)$ matrículas e direito com $508.424(13,1 \%)$. O número de concluintes nesses dois cursos foi de 63.688 alunos, representando 12,1\% do total de alunos concluintes de Ensino Superior.

Os censos 2005 e 2006 confirmam o predomínio dos cursos de graduação nessas áreas. Segundo o Censo 2005, dos 20.407 cursos de graduação presenciais existentes, 2.484 (12,17\%) eram de administração, enquanto em 2006, dos 22.101 cursos, 2.836 (12,83\%) eram de administração (considerando a área específica de gerenciamento e administração, dentro da área geral de ciências sociais, negócios e direito). Se considerada a área geral mencionada, estes cursos respondem por quase $30 \%$ da oferta total no Brasil. Em relação aos concluintes em 2006, dos 736.829 alunos, 40,61\% são dessa área geral e 16,58\% são da área específica citada. Entende-se que a predominância de determinados cursos em relação a outros se dá por diversos fatores, não estando somente relacionada à preferência profissional, mas também ao número de vagas ofertadas e ao custo financeiro dos cursos.

Algumas preocupações decorreram da rápida expansão dos cursos de administração no Brasil, como a quantidade de alunos formados em relação à 
absorção pelo mercado de trabalho, e a falta de qualidade em muitos cursos de graduação e pós-graduação. Em face dessa preocupação, algumas instituições concentraram esforços para analisar e melhorar a qualidade dos cursos de administração, como a Associação Nacional dos Cursos de Graduação em Administração (Angrad), o Conselho Federal de Administração (CFA), e a Associação Nacional de Pós-graduação e Pesquisa em Administração (Anpad).

No entanto, a história do Ensino Superior em administração no Brasil não é feita somente da história dos cursos tradicionais, de bacharelado. Em paralelo, houve também a expansão dos cursos tecnológicos em gestão.

\section{Os cursos superiores de tecnologia no Brasil}

Os cursos superiores de tecnologia nasceram na década de 1970, de forma tímida. A força de trabalho brasileira contou por muito tempo com trabalhadores carentes de qualificação. Com o processo de industrialização do país a partir dos anos 1950, e as crescentes inovações tecnológicas, as mudanças na organização da produção passaram a demandar profissionais "com escolaridade básica e com adequada e contínua qualificação profissional". Nesse contexto, o tecnólogo passou a ser requisitado (Parecer CNE/CP no 29/2002).

A origem dos CSTs foi respaldada pela Lei no $4.024 / 61$, a primeira LDB, que, em seu art. 104, contemplava "a organização de cursos ou escolas experimentais, com currículos, métodos e períodos escolares próprios". Em 1969, por meio do Decreto-lei no 547, foi autorizado o funcionamento dos cursos profissionais superiores de curta duração pelas escolas técnicas federais. Em São Paulo, nesse período, os cursos de tecnólogos ou cursos superiores de tecnologia foram criados e implementados inicialmente pelo Centro Estadual de Educação Tecnológica Paula Souza (CEETPS - MEC/Setec, Políticas públicas para a educação profissional e tecnológica, 2004).

A partir de 1972, o governo federal expandiu seu projeto em todo o país, criando em 1976 o Centro de Educação Tecnológica da Bahia (Centec/ BA) exclusivamente para a formação de tecnólogos, e, em 1978, os centros federais de educação tecnológica do Paraná, Minas Gerais e Rio de Janeiro.

A Lei no 5.692, de 11 de agosto de 1971, introduziu mudanças profundas na organização do sistema de ensino, no qual a educação profissional (denominada formação especial) passou a ser obrigatória para todos os estudantes. Essa mudança foi tanto uma resposta às necessidades de novos arranjos sociais que demandavam força de trabalho quanto uma resposta às críticas de um sistema educacional elitista e excludente. A profissão passou a 
ser destinada a todos que frequentavam o Segundo Grau, onde a habilitação para o trabalho, com conteúdos mínimos e carga horária definida, deveria predominar sobre a educação geral (Faustini, 2004). Nesse período, os CSTs foram incentivados pelo Projeto no 19, do Plano Setorial de Educação e Cultura para o período 1972-74, dada a constatação de que havia uma subutilização de profissionais formados nos cursos superiores tradicionais, e dada a necessidade de conduzir o estudante a uma rápida inserção no mercado de trabalho. Com isso, foram implantados 28 novos cursos em 19 instituições de ensino superior, principalmente em universidades e instituições federais. $\mathrm{O}$ diferencial desses cursos deveriam ser, de acordo com o Parecer CFE o 160/70, as características próprias de um curso voltado para a realidade tecnológica do mundo do trabalho. A Resolução Confea no 218/73 estabeleceu as competências e atribuições específicas ao técnico de nível superior ou tecnólogo das áreas de engenharia, arquitetura e agronomia, consistindo assim em um primeiro reconhecimento formal pelo mercado de trabalho do curso superior de tecnologia e dos tecnólogos.

O Projeto Setorial no 15, do Segundo Plano Setorial de Educação e Cultura para o período 1975-79, reforçou o incentivo aos CSTs e suas melhorias, porém, essas recomendações não foram amplamente acatadas, gerando a oferta de cursos sem os requisitos mínimos necessários para a qualidade esperada. Com isso, o Conselho Federal de Educação (CFE) passou a exigir, pela Resolução CFE no 17/77, a demonstração da necessidade do mercado de trabalho para a implantação dos cursos superiores de tecnologia, o perfil profissiográfico do formando, a determinação da estrutura curricular de acordo com o perfil, e a indicação do corpo docente e suas respectivas qualificações técnicas para tal (Parecer CNE/CP no 29/02).

Em 1973, o Parecer no CFE 1.060 registrou a denominação de "cursos superiores de tecnologia" e seus diplomados como "tecnólogos". Em 1974, pelo Decreto Federal no 74.708, foram reconhecidos os cursos ofertados pela Faculdade de Tecnologia de São Paulo (Fatec/SP) e do CEETESP. A Resolução CFE no 55, de 1976, estabeleceu o currículo mínimo para cursos de tecnologia em processamento de dados, o que prejudicou a adaptação necessária à evolução tecnológica. Essa fixação de currículos foi superada pela atual LDB, que a delega aos estabelecimentos de ensino, ficando definido pelo Parecer CNE/ CES no 436/01 as diretrizes curriculares nacionais orientadoras dos sistemas de ensino.

Em 1995, havia no Brasil 250 cursos tecnológicos, sendo a maioria ofertada pelo setor privado e mais da metade deles na área de computação (Pa- 
recer CNE/CES no 436/2001). O Decreto Federal no 97.333/88 autorizou a criação do primeiro CST em hotelaria pelo Senac de São Paulo, a partir do qual sua oferta foi se diversificando.

Apesar de a Lei no 8.948 já ter instituído o Sistema Nacional de Educação Tecnológica em 1994, foi somente com a LDB no 9.394/96 e o Decreto Federal no 2.208/97 que o ensino tecnológico ganhou nova dimensão e reiniciou sua trajetória no Ensino Superior brasileiro (Anet, 2003). As opiniões foram diversas sobre essas alterações legais, variando de uma avaliação positiva a negativa, como bem destacam Canopf, Festinalli e Ichikawa (2005). Para as autoras, enquanto Niskier (1997), por exemplo, analisa que o MEC, por meio da LDB, buscou pôr fim à indústria de currículos regulamentando a autorização de novos cursos superiores, outros autores, como Saviani (1997) e Demo (1998) criticam a nova lei por não ter criado um sistema nacional de educação aberto, abrangente e adequado, e por banalizar o ensino superior ao não vincular a avaliação de autorização e reconhecimento à intervenção e descredenciamento. Chauí (2001) acentuou a crítica ao associar a reforma da educação à reforma do Estado e, portanto, ao neoliberalismo (Canopf, Festinalli e Ichikawa, 2005).

Divergências à parte, cabe ressaltar neste artigo que a nova LDB possui quatro artigos que tratam da educação profissional entre os 92 existentes: arts. 39 a 42 . Outros artigos gerais também referenciam a relação com o mundo do trabalho, como o $\S 2^{\circ}$ do art. 10 "a educação escolar deverá vincular-se ao mundo do trabalho e à prática social". No entanto, a LDB não se refere à educação tecnológica, e sim à educação profissional em geral. Esta lacuna vem ser preenchida somente pelo Decreto no 2.208/97, que em seu art. 10 especifica a educação tecnológica: "os cursos de nível superior, correspondentes à educação profissional de nível tecnológico, deverão ser estruturados para atender aos diversos setores da economia, abrangendo áreas especializadas, e conferirão diploma de tecnólogo". No mesmo ano, fica regulamentado também a criação de centros de educação tecnológica (CET), públicos ou privados. De acordo com o art. $2^{\circ}$ do Decreto $\mathrm{n}^{\circ}$ 2.406/97, sua finalidade é

formar e qualificar profissionais, nos vários níveis e modalidades de ensino, para os diversos setores da economia e realizar pesquisa e desenvolvimento tecnológico de novos processos, produtos e serviços, em estreita articulação com os setores produtivos e a sociedade, oferecendo mecanismos para a educação continuada.

Após a publicação do Decreto no 2.208/97, houve ainda a publicação de uma série de instrumentos normativos que caracterizaram a reforma da 
educação profissional: Portaria/MEC no 646/97, Portaria/MEC no 1.005/97, Portaria/MEC/MTb no 1.018/97 e Lei Federal no 9.649/98 (MEC/Setec, Políticas públicas para a educação profissional e tecnológica, 2004). A partir de 2004, a educação profissional em vigor no Brasil, segundo o Decreto no 5.154 de 23 de julho de 2004, passou a consistir de três níveis:

I — formação inicial e continuada de trabalhadores;

II - educação profissional técnica de nível médio;

III - educação profissional tecnológica de graduação e de pós-graduação.

Assim, a educação profissional e tecnológica vem consolidar-se como um esforço estratégico do Ministério da Educação com vistas às mudanças que vêm ocorrendo no mundo do trabalho, na economia nacional e internacional, e nos sistemas sociais: "cursos superiores de tecnologia (...) uma das principais respostas do setor educacional às necessidades e demandas da sociedade brasileira" (Parecer CNE/CES no 436/2001). O Parecer no 29/2002 destaca que a educação tecnológica tem um papel especial nesse contexto "como requisito de formação básica de todo cidadão que precisa de instrumental mínimo para sobrevivência na sociedade da informação, do conhecimento e das inúmeras tecnologias cada vez mais sofisticadas". A educação tecnológica "pode ser considerada correspondente à educação profissional nos termos da atual legislação (...) pois os termos 'técnica' e 'tecnologia' estão presentes em todos os níveis da educação profissional". Assim como os cursos técnicos estão permeados pela tecnologia, "a técnica está presente tanto no nível tecnológico quanto nas demais habilitações de nível superior". Dessa forma, "a formação do tecnólogo requer desenvolvimento de competências mais complexas que as do nível técnico".

A seguir, algumas características dessa modalidade de ensino são descritas, uma modalidade que cresceu 10 vezes entre 1999 e 2004.

\section{Características dos cursos superiores de tecnologia}

O Parecer CNE/CES no 436/2001, aprovado pela Câmara de Educação Superior do Conselho Nacional de Educação, define os cursos superiores de tecnologia:

são cursos de graduação com características especiais, bem distintos dos tradicionais e cujo acesso se fará por processo seletivo, a juízo das instituições que os ministrem. Obedecerão a diretrizes curriculares nacionais a serem aprovadas pelo Conselho Nacional de Educação. 
Dessa forma, todos os CSTs são cursos de graduação, e seus concluintes ficam aptos a prosseguir seus estudos em nível de pós-graduação. As diretrizes curriculares nacionais gerais para a educação profissional de nível tecnológico foram definidas pelo Parecer ํㅡ 29/2002 e proposta de resolução anexa, homologado pelo ministro de Estado da Educação em 13 de dezembro de 2002. Além de definir os critérios e objetivos da educação tecnológica, as diretrizes também constituíram um esforço de romper com o preconceito histórico nacional de que a educação para o trabalho destina-se à formação profissional de classes sociais menos favorecidas, ofertando uma educação profissional de nível superior fundamentada no desenvolvimento do conhecimento tecnológico e na realidade do mundo do trabalho.

De acordo com a legislação, a principal diferença entre os cursos de graduação tecnológica, que conferem o diploma de tecnólogo, e os cursos tradicionais de Ensino Superior, que conferem o diploma de licenciatura ou bacharel, está na proposta de cada um. Os cursos tecnológicos vêm atender a uma demanda do mercado por especialistas dentro de uma área de conhecimento, em vez dos generalistas formados pelas outras modalidades de Ensino Superior.

Os principais atributos dos CSTs são o foco, a rapidez, a inserção no mercado de trabalho e a metodologia. $\mathrm{O}$ foco diz respeito à formação em um campo de trabalho definido, de acordo com as tendências do mercado. A rapidez refere-se à oferta do curso com uma carga horária menor, de dois ou três anos. Por estarem pautados em pesquisa de mercado para sua oferta e funcionamento, visam à rápida inserção do aluno no mercado de trabalho de acordo com suas tendências. A metodologia praticada abrange técnicas, métodos e estratégias focadas na aprendizagem, no saber e no saber-fazer, com propostas didático-pedagógicas voltadas para a prática. Por isso, os cursos tecnológicos não constituem cursos permanentes, mas sim cursos que devem ser continuamente revistos, redesenhados e reorganizados, para garantir a adequação à mutabilidade das necessidades do mercado de trabalho (Anet, 2003). Com essas características, os cursos tecnólogos não admitem um fluxograma linear e "engessado", requerendo assim flexibilidade de percurso e a possibilidade de certificações intermediárias para alunos que não tenham interesse ou não possam concluir o curso.

O art. 6o do Projeto de Resolução do Parecer nº 29/2002 define que

a organização curricular dos cursos superiores de tecnologia deverá contemplar o desenvolvimento de competências profissionais e será formulada em consonância com o perfil profissional de conclusão do curso, o qual define a identidade do mesmo e caracteriza o compromisso ético da instituição com os seus alunos e a sociedade. 
O §1ํe estabelece que "a organização curricular compreenderá as competências profissionais tecnológicas, gerais e específicas, incluindo os fundamentos científicos e humanísticos necessários ao desempenho profissional do graduado em tecnologia". De acordo com o Parecer no 29/2002,

o objetivo é o de capacitar o estudante para o desenvolvimento de competências profissionais que se traduzam na aplicação, no desenvolvimento (pesquisa aplicada e inovação tecnológica) e na difusão de tecnologias, na gestão de processos de produção de bens e serviços e na criação de condições para articular, mobilizar e colocar em ação conhecimentos, habilidades, valores e atitudes para responder, de forma original e criativa, com eficiência e eficácia, aos desafios e requerimentos do mundo do trabalho.

Para efeito desse parecer, alguém tem competência profissional "quando constitui, articula e mobiliza valores, conhecimentos e habilidades para a resolução de problemas não só rotineiros, mas também inusitados em seu campo de atuação profissional". Esse conceito de competências, que deve proporcionar condições de laborabilidade, exige a organização de um currículo atualizado.

Os currículos dos CSTs devem ter flexibilidade, interdisciplinaridade, contextualização e atualização permanente. A interdisciplinaridade evita a segmentação de conteúdos, pois nessa perspectiva os conhecimentos não são unidades isoladas. A contextualização implica relacionar conteúdo e contexto para dar significado ao aprendizado, privilegiando metodologias que integrem a vivência e a prática profissional. A atualização envolve a adequação da organização curricular às demandas sociais, do mercado, das peculiaridades locais e regionais, da vocação e da capacidade institucional, e, por isso, deverá enfocar as competências profissionais do tecnólogo e o perfil de conclusão pretendido (Parecer no 29/2002).

Uma das formas previstas de flexibilizar o currículo é a modularização, cujos módulos devem ser organizados sistematicamente para o desenvolvimento de competências. Dessa forma, pode haver entradas e saídas intermediárias, e certificação de qualificação profissional em módulos com terminalidade que permitam ao indivíduo algum tipo de exercício profissional. A instituição deve também prever mecanismos de avaliação das competências desenvolvidas em atividades fora da escola, no mundo do trabalho e na prática social, bem como de aproveitamento para fins de continuidade de estudos, considerando a "perspectiva de educação permanente e de contínuo desenvolvimento da capacidade de aprender e de aprender a aprender, com crescente grau de autonomia intelectual" (Parecer no 29/2002). 
Uma pesquisa realizada pela Associação Nacional da Educação Tecnológica (Anet) identificou algumas características do perfil dos alunos de cursos tecnológicos. Essa pesquisa, denominada perfil do tecnólogo, foi aplicada aos alunos matriculados nos centros de educação tecnológica participantes da associação, com o objetivo de definir o perfil do tecnólogo do Brasil. O total da amostra foi de 6.515 alunos pesquisados. Os resultados, apesar de restritos ao local de aplicação, ilustram o perfil dos alunos de cursos tecnlógicos: a idade média dos alunos é de 29 anos, sendo $64 \%$ do sexo masculino, $57 \%$ solteiros, $86 \%$ trabalham, sendo que destes $63 \%$ exercem atividades profissionais relacionadas com o curso que fazem, $20 \%$ atuam no comércio, $17 \%$ na tecnologia, $16 \%$ na indústria, $11 \%$ nos bancos, $5 \%$ em serviços e $5 \%$ na saúde. Desses alunos, 58\% nunca começou outro curso superior. As principais expectativas quanto aos cursos são: preparo para o mercado de trabalho (29\%), ascensão profissional (25\%), seguir carreira na área (18\%) e concluir o curso superior (15\%). São provenientes do Ensino Médio público 51\% dos alunos, 86\% pretendem fazer pós-graduação, $78 \%$ possuem computador em casa e $79 \%$ se mantêm com recursos próprios durante o curso.

Os CSTs podem ser ofertados por universidades, centros universitários, faculdades integradas, faculdades isoladas e institutos superiores. Da mesma forma, poderão ser ofertados por centros de educação tecnológica públicos e privados. As instituições de ensino público têm autonomia para abertura dos CSTs, mas precisam passar por um processo de avaliação para fins de reconhecimento de curso. Já as instituições de ensino privadas precisam passar por processos de avaliação tanto para fins de autorização de funcionamento quanto para reconhecimento de curso. A Portaria MEC no 1.647/99, considerando o disposto na Lei ํㅜ 9.131/95, na Lei no 9.394/96 e no Decreto no 2.406/97, dispõe sobre o credenciamento dos CETs e a autorização de cursos de nível tecnológico da educação profissional.

Sobre a regulação da oferta de CSTs, em maio de 2004 o MEC suspendeu a abertura de novas instituições por seis meses a fim de garantir a qualidade no ensino. Nesse período, cerca de 5 mil pedidos de novos cursos e 520 propostas para criação de novas instituições estavam em andamento. Em agosto do mesmo ano, o MEC adotou novas regras para autorizar novos cursos. Para o pedido de credenciamento, as instituições precisam atender às necessidades da região e ofertar um número de vagas correspondente à infraestrutura apresentada no momento do pedido. Muitas instituições de ensino solicitavam abertura de vários cursos para criar uma reserva de vagas, apesar de conseguir manter apenas alguns.

A Portaria MEC no 3.643/2004 determinou que os pedidos de autorização para cursos tecnológicos devem ser protocolados por meio do Sistema de 
Acompanhamento de Processos das Instituições de Ensino Superior (Sapiens). Os novos processos puderam ser protocolados a partir de 2 de janeiro de 2005. Dessa forma, a partir de 3 de janeiro, todos os processos referentes ao credenciamento/recredenciamento de faculdades de tecnologia (nova denominação dos CETs), assim como todos os processos referentes aos CSTs (autorização, reconhecimento, renovação de reconhecimento, aumento de vagas, mudança de endereço e outros) passaram a ser protocolados pelo Sapiens. A sistemática de avaliação também foi alterada. Todos os processos de avaliação passaram a ser coordenados pelo Inep. O preenchimento dos dados resultantes da avaliação, feita por especialistas do MEC, passou a ser feito eletronicamente. Enquanto anteriormente os especialistas emitiam um parecer consultivo, agora eles registram apenas os resultados da avaliação.

Novas regulamentações foram elaboradas normatizando as funções de regulação, supervisão e avaliação de cursos e instituições de graduação, como o Decreto no 5.773, de 9 de maio de 2006, e o Decreto no 5.840 , de 13 de julho de 2006. Mais recentemente, a Portaria Normativa MEC no 40, de 12 de dezembro de 2007, instituiu o e-MEC, um sistema eletrônico de fluxo de trabalho e gerenciamento de informações relativas aos processos de regulação da educação superior no sistema federal de educação.

Sobre as áreas de oferta e denominação dos cursos tecnológicos, conforme o Parecer CNE/CES no 436/2001, os CSTs poderiam ser ofertados dentro de 20 áreas profissionais. No entanto, devido à grande diversidade de CSTs ofertados, as possibilidades foram repensadas e circunscritas a 10 áreas. Estas são atualmente definidas pelo Catálogo Nacional dos Cursos Superiores de Tecnologia, publicado em 2006. São elas: produção alimentícia; recursos naturais; produção cultural e design; gestão e negócios; infraestrutura; controle e processos industriais; produção industrial; hospitalidade e lazer; informação e comunicação; e ambiente, saúde e segurança. Cada área tem suas diretrizes e a carga horária mínima obrigatória. Dentro da área de gestão e negócios, podem ser ofertados cursos superiores de tecnologia em: comércio exterior, gestão comercial, gestão da qualidade, gestão de cooperativas, gestão de recursos humanos, gestão financeira, gestão pública, logística, marketing, negócios imobiliários, processos gerenciais e secretariado. No entanto, cabe a todos os CSTs promover o desenvolvimento da capacidade empreendedora e de competências profissionais e tecnológicas para a gestão de processos e a produção de bens e serviços (Parecer no 29/2002).

Dadas as alterações e constantes revisões legais da educação profissional, em geral, e da educação profissional tecnológica, em específico, a oferta de CSTs apresentou um rápido crescimento da oferta e da absorção dos tecnólogos pelo mercado de trabalho. 


\section{Crescimento dos cursos superiores de tecnologia}

Em 1998, o Brasil contava com 104 mil alunos em 554 CSTs. Deste total, $32 \%$ eram de processamento de dados; $14 \%$ de turismo; $11 \%$ de secretariado executivo; $7 \%$ de análise de sistemas; $5 \%$ de zootecnia e $31 \%$ de outras modalidades. Ao todo, existiam 70 modalidades diferentes em todas as áreas profissionais (Parecer CNE/CES no 436/2001).

A nova dimensão dada aos CSTs pela Lei no $9.394 / 96$ e pelo Decreto Federal no 2.208/97 proveu organização e incentivo a essa modalidade educacional. As políticas públicas do MEC nos últimos anos trouxeram uma nova perspectiva de formação superior para o Brasil que já existe em outros países.

O aumento da oferta dos CSTs em CETs e faculdades de tecnologia ilustra o crescimento desses cursos no Brasil. Conforme dados do Inep, em 1999 somente essas instituições ofertavam 74 cursos no país. Em 2001, esse número passou para 183, um crescimento de 147,3\%. Em 2003, havia 495 cursos representando 170,5\% de crescimento em relação a 2001 e 568,9\% em relação a 1999. De acordo com o Censo da Educação Superior de 2004, realizado em 2005, essas IES ofertavam 758 cursos, o que indica que, em seis anos, o Brasil decuplicou o número de cursos oferecidos por essa modalidade de organização acadêmica. O crescimento continuou em 2005, quando o Censo da Educação Superior de 2006 identificou a oferta de 959 cursos tecnológicos presenciais. Contudo, há outras instituições de ensino que ofertam tais cursos, além dos CETs. A figura ilustra esses dados.

\section{Evolução dos cursos nos centros de educação tecnológica no Brasil}

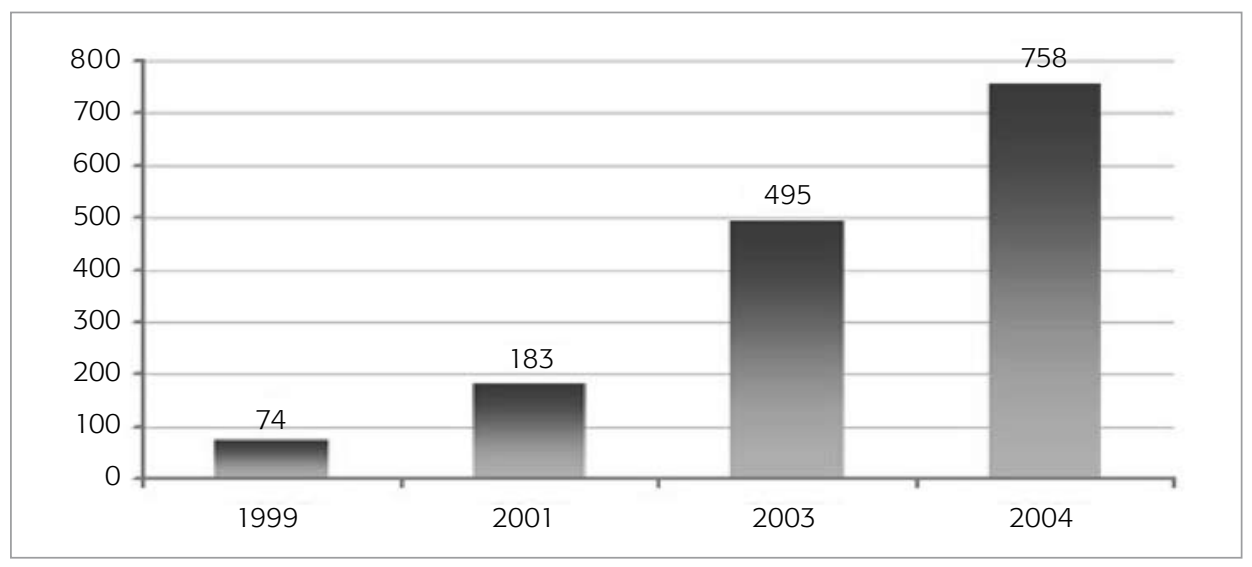

Fonte: Inep/MEC. Disponível em: <www.inep.gov.br> (2005). 
Nesses números observa-se a participação do setor privado de ensino, que em 2001 ofertava 30 cursos e em 2003, 181; um crescimento de 503,3\%. Em 2004 foram criados mais 209 cursos na rede privada. Dos 758 CSTs ofertados nos CETs em 2004, 51,8\% pertenciam ao setor privado e 48,2\% ao setor público.

A partir de 2004, as escolas agrotécnicas federais também obtiveram a permissão pelo CNE/MEC, em caráter experimental, para abrir cursos tecnológicos. Conforme a reportagem do Paraná on-line - PR, de 12 de fevereiro de 2005, a coordenadora geral de Educação Profissional e Tecnológica da Setec/MEC, Andréa de Faria Barros Andrade, aponta como principais motivos da expansão desses cursos o fato de estarem muito próximos do mercado de trabalho e de refletirem as características das regiões onde estão inseridos: "desde a sua denominação, eles tentam mostrar a que demanda estão vinculados. Acompanham a tendência mundial". Exemplos desta contextualização são os CSTs de viticultura e enologia, em Bento Gonçalves (Rio Grande do Sul), de alimentos, em Chapecó (Santa Catarina), de produção moveleira, em Votuporanga (São Paulo), de irrigação e drenagem em Iguatu (Ceará), e o de produção de cachaça em Salinas (Minas Gerais).

O Censo da Educação Superior 2004 apontou a distribuição dos CSTs presenciais segundo o tipo de instituição de ensino. As universidades, públicas ou privadas, ficaram em primeiro lugar sendo responsáveis pela maioria dos cursos de educação tecnológica (38,14\%). Os CETs e as faculdades tecnológicas vêm logo a seguir, concentrando 36,70\% do total de 1.804 cursos desse tipo existentes no Brasil. Já as faculdades, escolas e institutos, que em 1998 promoviam 55,81\% dos cursos de educação tecnológica, atualmente respondem por 8,92\%. A tabela mostra essa distribuição.

A educação superior tecnológica diplomou um total de 11.759 estudantes, representando 1,9\% dos 626.160 graduados da educação superior em 2004. O Censo 2006 não aponta os dados sobre os CSTs considerando-se todos os tipos de instituições de ensino. Nos CETs e faculdades tecnológicas, o número de ingressos em CSTs presenciais foi de 50.682 em 2005, sendo 37,24\% no setor público e $62,76 \%$ no setor privado. Ao total, foram ofertadas 90.894 vagas nessas instituições, o que significa que apenas 40.212 (55,76\%) foram preenchidas. Ao analisar a distribuição por setor, foi possível verificar que 95,4\% das vagas no setor público foram preenchidas, enquanto no setor privado foram preenchidas 43,63\%. O total dos concluintes nessas instituições em 2005 foi de 18.253 alunos. Cabe ressaltar que, apesar de esses dados fornecerem informações relevantes sobre a oferta e o crescimento dos cursos tecnológicos no Brasil, seria necessário ter dados atuais sobre a oferta dessa modalidade de ensino em todas as instituições de ensino para uma análise mais precisa. O mesmo ocorre na análise de dados sobre os cursos na área de gestão e negócios. 


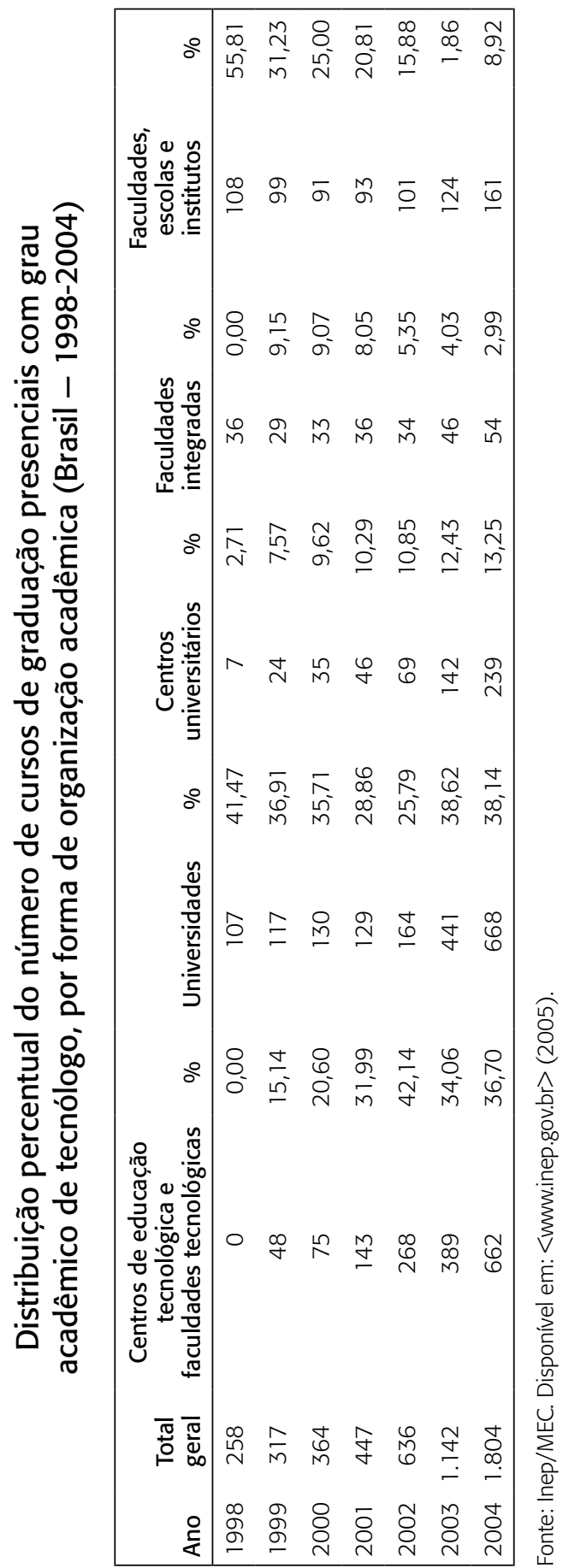




\section{Os cursos superiores de tecnologia na área de gestão}

Pesquisas realizadas nos sites oficiais do Ministério da Educação, Censo do Ensino Superior (Inep), revistas especializadas em educação, revistas da área de administração e internet não permitiram identificar o número exato de instituições, cursos e alunos dos CSTs na área de gestão. O último Censo da Educação Profissional foi realizado em 1999, não retratando, portanto, a expansão recente da educação tecnológica. Sabe-se, no entanto, que, nas estatísticas sobre o ensino superior de forma geral, a área de administração tem predominado. De acordo com a participação da autora como avaliadora dos CSTs na área de gestão desde 2003, esse predomínio também pode ser percebido.

Alguns dados do Censo 2006 podem ser analisados com as mesmas limitações apontadas anteriormente. Eles identificam dados dos cursos tecnológicos nos CETs e faculdades tecnológicas, mas não apontam dados que considerem todas as instituições ofertantes. Entre os 18.253 concluintes em 2005, a maioria está na grande área de ciências sociais, negócios e direito: 8.866 alunos. Destes, 6.568 concluintes estão na área específica de administração, $36 \%$ do total.

Os CSTs na área de gestão apresentam claras diferenças em relação aos cursos de bacharelado em administração. A organização curricular dos bacharelados privilegia o conhecimento em suas diversas áreas, abrangendo inúmeros focos de forma generalista, enquanto currículos de cursos tecnológicos privilegiam unidades curriculares dentro de uma determinada área de conhecimento. Dessa forma, um exemplo de organização curricular de CST em gestão financeira poderia ser:

\section{Quadro 2}

\section{Grade curricular de um CST em gestão financeira}

\begin{tabular}{|ll}
\hline Planejamento financeiro & Informatização empresarial | 80h \\
& - Fundamentos de contabilidade | 120h \\
& Fundamentos de finanças | 80h \\
& - Gestão em empresa moderna | 120h \\
& - Fundamentos de gestão | 80h \\
Análise de crédito & Planejamento estratégico financeiro | 120h \\
& Matemática financeira | 80h \\
& - Economise dos demonstrativos financeiros | 120h \\
& - Análise de risco e crédito | 120h
\end{tabular}




\begin{tabular}{|ll|}
\hline Investimentos & $\boldsymbol{\nabla}$ Administração do circulante | 120h \\
& $\boldsymbol{\nabla}$ Elaboração de orçamento | 80h \\
& $\boldsymbol{\nabla}$ Análise e decisão de investimentos | 120h \\
& $\boldsymbol{\nabla}$ Legislação tributária | 80h \\
& $\boldsymbol{\nabla}$ Desenvolvimento de projetos financeiros | 120h \\
\hline
\end{tabular}

Fonte: Grupo Opet. Disponível em: <www.opet.com.br/superior/reboucas_cursos.asp>. Acesso em: abr. 2006.

Neste caso, pode-se observar que os três módulos estão organizados em torno de um eixo comum, no caso gestão financeira, e as disciplinas são agrupadas em módulos segundo as áreas de atividade. Por isso, o projeto pedagógico do curso, em geral, e a organização curricular, em específico, devem estar em sintonia com a justificativa da oferta (demanda dos profissionais no mercado de trabalho, novas formas de trabalho e de produção, características de avanço tecnológico do setor, postos de trabalho e atividades correspondentes, e dados socioeconômicos da região), a finalidade e os objetivos do curso, e o perfil profissional de conclusão esperado do aluno.

Em suma, apesar da escassez de informações existentes sobre os cursos tecnológicos específicos da área de gestão, em parte justificável pelo seu crescimento recente nos últimos anos, pode-se perceber que os CSTs em geral têm se consolidado no setor educacional brasileiro, não representando um modismo como foram, por exemplo, os cursos sequenciais. Dada essa inserção e expansão no setor educacional, busca-se então refletir sobre possíveis impactos no cenário da formação superior em administração no Brasil, tanto em nível de graduação como de pós-graduação.

\section{Discussões e reflexões}

A educação superior no Brasil consolidou-se nas últimas décadas e, em especial, na área de administração, nos últimos 50 anos. Atualmente, ela representa o campo de conhecimento mais ofertado para formação superior, o que lhe traz benefícios e restrições.

\section{Para o ensino em administração no Brasil}

No âmbito nacional, enquanto os cursos tradicionais de administração expandiram-se a partir dos anos 1980, principalmente no setor privado, os cursos profissionais de nível tecnológico foram marcados pela dificuldade de implan- 
tação e legitimação. Apesar de existirem desde os anos 1970, somente na última década é que eles realmente se consolidaram. A partir de tal fato, o panorama do ensino superior é profundamente alterado. Mesmo representando uma porcentagem pequena diante dos cursos tradicionais, a taxa de crescimento dos CSTs tem sido superior à taxa de crescimento dos cursos de bacharelado. Esse cenário, entretanto, não se modifica por acaso. Ele coincide com os esforços de expansão da educação profissional no Brasil por meio das estratégias governamentais, acompanhando algumas tendências mundiais.

De acordo com Stern (1996), a educação profissional está sendo reformulada em diversos países de forma combinada com a educação acadêmica, o que reflete a convergência do trabalho e da aprendizagem no local de trabalho. Nos Estados Unidos há uma proliferação de novos programas delineados para integrar a educação acadêmica e profissional, como, por exemplo, o teach prep, que combina o currículo acadêmico e profissional e também liga os dois últimos anos do secondary school com os dois primeiros anos do postsecondary educational. O Japão tem desenvolvido um novo currículo integrado acadêmico-profissional para a high school, que até 1994 oferecia somente um currículo geral como preparação para a universidade ou um currículo profissional especializado. A França tem criado uma variedade de diplomas secundários superior: geral, técnico e profissional. A partir de 1985, ela inseriu o diploma profissional, oferecendo aos graduados de programas profissionais de dois anos a opção de receber um diploma secundário-superior após um adicional de dois anos. Na Alemanha, um sistema duplo de aprendizagem tem sido amplamente aceito como um modelo de sucesso para iniciar a educação profissional. O Reino Unido introduziu um novo conjunto de qualificações profissionais denominado general national vocational qualifications (GNVQs), procurando remover barreiras para equalizar o status entre o percurso acadêmico e profissional.

Diversos outros exemplos podem ser citados na busca do novo enfoque de educação e trabalho (Stern, 1996). A Suécia requer que estudantes do novo programa secundário superior de três anos passem 15\% do seu tempo em locais de trabalho. A Austrália está criando o student traineeships para permitir que estudantes combinem os estudos da escola com a experiência do trabalho e o treinamento fora do local de trabalho. O Reino Unido lançou uma iniciativa para criar modern apprenticeships para estudantes de 16-17 anos que terminam a escola, onde programas foram desenvolvidos em $1994 \mathrm{em} 12$ setores. A Coreia tem reestruturado seu currículo de high school profissional para incluir um ano em empresas nos programas de três anos. Nos Estados Unidos, o School-to-Work Opportunities Act, em 1994, forneceu recursos federais para 
os estados implementarem novos sistemas de escola para o trabalho, onde a aprendizagem baseada no trabalho é o componente necessário.

Mediante tal comparativo, a estratégia de fomento da educação profissional parece ser positiva para a inserção e qualificação de trabalhadores no sistema educacional e, por conseguinte, para a inserção do Brasil na chamada economia baseada em conhecimento (Dahlman, 2002; Castells, 1999; OCDE, 1996), uma vez que nela a educação recebe especial destaque. Em alguns países, a maioria dos alunos é formada em cursos superiores de tecnologia. De acordo com o Parecer CNE/CES no 436/2001, nos Estados Unidos e em alguns países da Europa, essa modalidade educacional abrange metade dos alunos do Ensino Superior. Essa realidade ainda é recente no Brasil quando vista sob a ótica da nova LDB e suas posteriores regulamentações. Comparados aos cursos tradicionais, de licenciatura e bacharelado, ainda são a minoria. Porém, um rápido crescimento tem sido observado nos últimos cinco anos.

Em abril de 2004, o MEC/Setec publicou o documento Políticas públicas para a educação profissional e tecnológica, reafirmando o papel estratégico dessa modalidade dentro de sua política econômica nacional. ${ }^{1}$ Neste documento, o sistema educacional é apontado como historicamente localizado e circunstanciado, no qual circulam movimentos de construção e reconstrução, determinados por fatores de ordem econômico-social e político-cultural. Com isso,

o objetivo maior deste documento é o de estabelecer diretrizes e definir políticas públicas para a educação profissional e tecnológica visando à consolidação de ações efetivas que redundem no aperfeiçoamento da democracia, na melhor qualificação do cidadão, jovem ou trabalhador, na redução das desigualdades sociais e na sua participação como agente de transformação para construir o desenvolvimento do Brasil.

Os efeitos de tais mudanças têm sido a gradual inserção dos tecnólogos no mercado de trabalho. Essa inserção tem mudado lentamente o preconceito histórico associado aos cursos de formação profissional, conferindo reconhecimento social aos mesmos. Trata-se de uma caminhada, um processo que vem ocorrendo na sociedade nestes últimos anos.

\footnotetext{
${ }^{1}$ Esse quadro de princípios orientadores, apresentado nesse documento que tem como objetivo estabelecer diretrizes e definir políticas públicas para a educação profissional e tecnológica, resultou do Documento-base e do Relatório Final do Seminário Nacional de Educação Profissional (2003).
} 
Apesar de os resultados da expansão da educação profissional, no âmbito nacional, parecerem positivos, embora haja também o debate sobre sua qualidade, deve-se ainda questionar sobre o efeito dessa expansão em áreas específicas do conhecimento. É o caso desse estudo no campo da administração. Ou seja, trata-se de questionar em que medida a expansão e consolidação dos CSTs em gestão importam ou trazem preocupações para a área de administração, e que implicações o surgimento dos CSTs têm para os acadêmicos e práticos, para os docentes e para os alunos.

A administração tem se destacado nas estatísticas tanto pela liderança na oferta de cursos, bacharelados e tecnológicos, quanto pela liderança na preferência de alunos. Respondendo à demanda, as instituições têm ampliado a gama de opções de cursos dentro da área de administração, trazendo profundas implicações para os profissionais do campo.

\section{Para as instituições de ensino ofertantes de CSTs e docentes}

No âmbito acadêmico, tal fato chama a atenção para uma reflexão: se essa modalidade de ensino tem se consolidado como mostram as pesquisas, professores e pesquisadores de administração precisam conhecer melhor sua estrutura, compreender sua proposta pedagógica e curricular, entender as demandas discentes, e, principalmente, adaptar suas práticas de ensino. No caso de CSTs, privilegiam-se as dinâmicas e estratégias didáticas que permitam vincular teoria e prática. Esse é o caso, por exemplo, de metodologias como estudos de caso, redes como ambiente de aprendizagem, visitas técnicas, uso de laboratórios, entre outras. As características desses cursos, apresentadas anteriormente, e as demandas dos alunos, que têm um perfil diferenciado dos que frequentam cursos de bacharelado, requerem outra postura do professor de educação profissional de nível superior. Assim, uma questão a ser investigada é sobre a existência de docentes com tal perfil no grupo total de docentes em administração. Se sim, cabe verificar como esses docentes têm atuado no processo de ensino-aprendizagem; se não, cabe analisar como tem sido o ensino nos CSTs. Ou seja: estariam esses cursos sendo realmente diferenciados conforme a proposta apresentada na legislação e nas diretrizes, ou seriam uma adaptação dos cursos tradicionais de bacharelado? Em suma, que competências os cursos tecnológicos demandam dos coordenadores e docentes para atuar nos cursos tecnológicos de graduação?

Ainda na esfera acadêmica, uma segunda questão a ser levantada referese à continuidade dos estudos de tecnólogos. Ou seja, se os alunos formados 
em cursos tecnológicos podem, legalmente, prosseguir seus estudos em cursos de pós-graduação lato sensu e stricto sensu, cabe questionar como os cursos de pós-graduação têm tratado os candidatos que são tecnólogos. Se eles têm sido selecionados, como tem sido seu desempenho? Qual tem sido sua contribuição para a produção acadêmica em administração? No caso dos cursos de mestrado, em especial, pode-se ainda investigar se há congruência entre o crescimento dos cursos de mestrado profissional e o crescimento do número de concluintes em CSTs. Esses cursos de pós-graduação seriam o caminho mais provável para formados em cursos tecnológicos? Se sim, poderia-se esperar, em contrapartida, um crescimento acelerado nos cursos de mestrado profissional? Por sua vez, esse crescimento demandaria que perfil de docentes de pós-graduação? Que impacto esses (novos) cursos terão para os atuais cursos de pós-graduação em administração que se congregam na Anpad?

Uma terceira questão no nível acadêmico diz respeito à qualidade dos cursos tecnológicos, muito embora essa preocupação tangencie todos os níveis de ensino e tipos de cursos de administração. Dessa forma, caberia investigar de que maneira esses cursos têm sido avaliados e que resultados têm apresentado como resposta às políticas públicas de regulamentação (autorização, reconhecimento e pós-reconhecimento). Essa preocupação com a qualidade está expressa na crítica que autores como Saviani (1997), Demo (1998) e Chauí (2001), citados por Canopf, Festinalli e Ichikawa (2005), fizeram a respeito das reformas legais na educação a partir da LDB.

\section{Para a própria modalidade de ensino e para os alunos}

Uma reflexão relevante é sobre o impacto dessa realidade no campo prático da administração. É sabido que há um contingente significativo de alunos concluintes em administração (bacharelado) todos os anos, principalmente nas grandes capitais. Reunindo-se esse número ao número de concluintes de CSTs em gestão, emerge uma questão: há paralelismo entre a quantidade total de profissionais formados e de vagas no mercado de trabalho? Há sobreposição de funções nas organizações entre os tecnólogos e os administradores com especialidade adquirida nos cursos de pós-graduação lato sensu? Essas questões parecem conduzir a uma reflexão sobre a própria validade e adequação de cursos tecnológicos na área de administração. Para alimentar esse debate, há de se levar em conta as pesquisas que mostram a significativa falta de qualificação dos trabalhadores em geral para ocupar os postos de trabalho disponíveis no Brasil, e a falta de profissionais com formação em nível superior. 
Outras questões podem ser formuladas nessa categoria, que permanecem por investigar: como o mercado de trabalho vem recebendo ou receberá estes profissionais? Os CSTs têm qualificado profissionais especialistas para atender às demandas específicas do setor produtivo? O crescimento dos CSTs promove outra vertente, prática, da administração não atendida anteriormente? A expansão da educação tecnológica de nível superior deverá acelerar a produção, difusão e aplicação do conhecimento em administração? Os cursos tecnológicos poderão ser extintos ou reduzidos significativamente no Brasil nos próximos anos? Haverá um crescimento prejudicial ao campo de administração pelo excesso de "mão de obra" qualificada? Os CSTs estão crescendo pelo apelo mercadológico de curta duração e, por isso, podem estar prejudicando a qualidade dos profissionais? Certamente, todas essas questões merecem atenção e acompanhamento, uma vez que os estudos têm apontado para a continuidade e consolidação dos cursos superiores de administração no Brasil.

\section{Considerações finais}

O crescimento dos cursos superiores de tecnologia em gestão está contido no cenário de expansão do ensino superior em administração. O aumento na oferta dessa modalidade de ensino de graduação está vinculado, por sua vez, às reformas ocorridas no sistema educacional e, num âmbito maior, às configurações socioeconômicas e políticas do país, que busca alinhar suas estratégias educacionais ao contexto internacional e às pressões exercidas pela EBC para inserção na economia chamada globalizada. Tal crescimento, acelerado, incita reflexões sobre os possíveis impactos para o ensino em adminsitração no Brasil, para as instituições de ensino e docentes, para os alunos e para a própria modalidade de ensino.

Com base nas referências consultadas e nos dados secundários analisados, este artigo não teve a intenção de fornecer respostas para tais reflexões, muitas vezes apresentadas na forma de perguntas de pesquisa. Teve sim o propósito de jogar luz em um fenômeno atual no campo da administração e apresentar questionamentos que possam subsidiar a composição de uma agenda de pesquisas com vistas ao acompanhamento do crescimento da oferta dos CSTs em administração e de seu impacto na atuação de docentes, pesquisadores e tecnólogos da comunidade acadêmica e prática. As implicações da expansão da oferta dessa modalidade de ensino no Brasil, a exemplo do que ocorre em outros países, podem trazer diferentes resultados que merecem ser 
avaliados. Para isso, foi necessário descrever as características de uma (nova) modalidade de ensino que vem crescendo "vertiginosamente" no Brasil. Esse objetivo teve o papel de esclarecer suas especificidades e sua inserção no sistema educacional. Em um segundo momento, verificou-se a posição da área de administração na oferta e procura dos cursos superiores, tanto de bacharelado quanto de tecnologia.

Diversas pesquisas são ainda necessárias para explorar os questionamentos levantados. Alguns futuros estudos que podem contribuir envolvem pesquisar a comparação entre currículos e práticas pedagógicas de cursos tecnológicos e de bacharelado; a concepção de currículos para os cursos tecnológicos em gestão; a construção e compreensão de estratégias metodológicas; a avaliação apropriada para as metodologias de ensino desses cursos; a avaliação das políticas públicas brasileiras na educação profissional e tecnológica de graduação e pós-graduação em administração; o grau de conhecimento e concordância dos docentes e pesquisadores de administração sobre esses cursos; as competências necessárias das instituições de ensino ofertantes de CSTs e dos docentes.

Em suma, neste artigo, a contribuição a ser dada é divulgar a realidade apresentada e inseri-la na agenda de debates sobre ensino e pesquisa em administração de forma a acompanhar os impactos da expansão dos cursos tecnológicos em gestão para a própria modalidade, para a academia, para as instituições de ensino, para os docentes e para os alunos. De forma mais ampla, também para as políticas públicas voltadas para essa área, uma vez que estas necessitam de contínuo acompanhamento e adequação.

\section{Referências}

ANET (Associação Nacional de Educação Tecnológica). Educação profissional de nível tecnológico. Maio 2003.

BRASIL. Ministério da Educação. Parecer n. 160, 1970.

. Ministério da Educação. Resolução Confea n. 218/73.

. Lei n. 9.394/96, de 20 de dezembro de 1996. Estabelece as diretrizes e bases da educação nacional.

. Decreto n. 2.208, de 17 de abril de 1997. Regulamenta o $§ 2^{\circ}$ do art. 36 e os arts. 39 a 42 da Lei Federal n. 9.394/96, que estabelece as Diretrizes e Bases da Educação Nacional. 
. Decreto n. 2.406, de 27 de novembro de 1997. Regulamenta a Lei Federal n. 8.948/94 (trata de centros de educação tecnológica).

. Ministério da Educação. Parecer n. 436, 2001.

. Ministério da Educação. Parecer n. 29, 2002.

BRASIL. Ministério da Educação. Decreto n. 5.154, 2004.

CANOPF, L.; FESTINALLI, R. C.; ICHIKAWA, E. Y. A expansão do ensino superior em administração no sudoeste do Paraná: reflexões introdutórias. Revista de Administração Contemporânea, v. 9, n. 3, p. 79-97, jul./set. 2005.

CASTELLS, M. A era da informação: economia, sociedade e cultura. A sociedade em rede. São Paulo: Paz e Terra, v. 1, p. 86-221, 1999.

CASTRO, C. de M. O ensino da administração e seus dilemas: notas para debates. Revista de Administração de Empresas, Rio de Janeiro, v. 21, n. 3, p. 58-61, jul./set. 1981.

COELHO, F. S. Uma radiografia do ensino de graduação em administração pública no Brasil (1995-2006). In: ENCONTRO ANUAL DA ANPAD, 32., Rio de Janeiro, 2008. Anais... Rio de Janeiro: Anpad, 2008.

COUVRE, M. L. M. A formação e a ideologia do administrador de empresas. Petrópolis: Vozes, 1982.

CRA-SP (CONSELHO REGIONAL DE ADMINISTRAÇÃO). Histórico do ensino de administração. Disponível em: <www.crasp.com.br/biblioteca/historico_ensino_adm. html>. Acesso em: abr. 2006.

DAHLMAN, C. J. A economia do conhecimento: implicações para o Brasil. In: VELLOSO, J. P. R. (Org.). O Brasil e a economia do conhecimento. Rio de Janeiro: José Olympio, 2002. p. 161-196.

FAUSTINI, L. A. Estrutura administrativa da educação básica. In: MENESES, J. G. C. et al. (Orgs.). Estrutura e funcionamento da educação básica. 2. ed. São Paulo: Pioneira Thomson Learning, 2004. p. 137-151.

FISCHER, T. M. D. A difusão do conhecimento sobre organizações e gestão no Brasil: seis propostas de ensino para o decênio 2000/2010. Revista de Administração Contemporânea, Edição Especial, p. 123-139, 2001.

FRIGA, P. N.; BETTIS, R. A.; SULLIVAN, R. S. Mudanças no ensino em administração: novas estratégias para o século XXI. Revista de Administração de Empresas, v. 44, n. 1, p. 96-115, jan./mar. 2004. 
INEP (Instituto Nacional de Estudos e Pesquisas). Diretoria de Estatísticas e Avaliação da Educação Superior. Censo da Educação Profissional, 1999. Disponível em: $<$ www.inep.gov.br>. Acesso em: abr. 2008.

MARTINS, C. B. Surgimento e expansão dos cursos de administração no Brasil (1952-1983). Ciência e Cultura, São Paulo, v. 41, n. 7, p. 663-676, jul. 1989.

MINISTÉRIO DA EDUCAÇÃO. Instituto Nacional de Estudos e Pesquisas. Diretoria de Estatísticas e Avaliação da Educação Superior. Censo da educação superior, 2003a.

. Secretaria de Educação Profissional e Tecnológica. Subsídios para a discussão de proposta de anteprojeto de lei orgânica da educação profissional e tecnológica. 2003b.

. Secretaria de Educação Profissional e Tecnológica. Pacto pela valorização

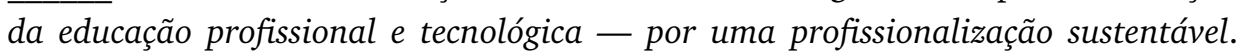
Proposta de Agenda Mínima Pactuada MEC/Setec, 2003c.

. Instituto Nacional de Estudos e Pesquisas. Diretoria de Estatísticas e Avaliação da Educação Superior. Censo da educação superior, 2004a.

. Secretaria de Educação Profissional e Tecnológica. Políticas públicas para a educação profissional e tecnológica. Brasília, abr. 2004b.

. Instituto Nacional de Estudos e Pesquisas. Diretoria de Estatísticas e Avaliação da Educação Superior. Censo da educação superior, 2005.

. Instituto Nacional de Estudos e Pesquisas. Diretoria de Estatísticas e Avaliação da Educação Superior. Censo da educação superior, 2006a.

. Catálogo Nacional dos Cursos superiores de tecnologia. 31 jul. 2006b.

. Educação profissional - legislação básica. 2001. Disponível em: <http:// portal.mec.gov.br/setec/arquivos/pdf/LegisBasica.pdf> . Acesso em: mar. 2008.

OCDE (Organização para a Cooperação e Desenvolvimento Econômico). The knowledge-based economy. Paris: OCDE, 1996.

OLIVEIRA, F. B.; SAUERBRONN, F. F. Trajetória, desafios e tendências no ensino superior de administração e administração pública no Brasil: uma breve contribuição. RAP, v. 41, Edição Especial Comemorativa, p. 149-170, 2007.

SEMINÁRIO NACIONAL DE EDUCAÇÃO PROFISSIONAL. Documento base. Brasília, 2003. Disponível em: <www.bvseps.epsjv.fiocruz.br/html/pt/seminarioeducacaoprofissional.htm>. Acesso em: maio 2010. 
SILVA; M. R.; FISCHER, T. Ensino de administração: um estudo da trajetória curricular de cursos de graduação. In: ENCONTRO ANUAL DA ANPAD, 32., Rio de Janeiro, 2008. Anais... Rio de Janeiro: Anpad, 2008.

STERN, D. Human resource development in the knowledge-based economy: roles of firms, schools, and governments. In: Employment and growth in the knowledgebased economy. Paris: OECD Documents, p. 189-206, 1996.

TORRECILLAS, G. L. S.; MIRAMAR, R. M. V. Educação a distância na administração e em outras graduações: a experiência de uma IES do Distrito Federal. In: ENCONTRO ANUAL DA ANPAD, 32., Rio de Janeiro, 2008. Anais... Rio de Janeiro: Anpad, 2008.

VIANA, A. B. N.; MANTOVANI, D. M. N.; VIEIRA, A. R. Análise dos programas de pós-graduação avaliados pela Capes: relação entre conceitos dos programas e índice de publicação. In: ENCONTRO ANUAL DA ANPAD, 32., Rio de Janeiro, 2008. Anais... Rio de Janeiro: Anpad, 2008.

WOOD JR., T.; PAULA, A. P. P. O fenômeno dos MPAs brasileiros: hibridismo, diversidade e tensões. Revista de Administração de Empresas, v. 44, n. 1, p. 116-229, jan./mar. 2004. 